International Journal of Building Pathology and Adaptation

emerald

PUBLISHING

International Journal of Building Pathology and Adaptation

Failure is an option: an innovative engineering curriculum

\begin{tabular}{|r|l|}
\hline Journal: & International Journal of Building Pathology and Adaptation \\
\hline Manuscript ID & IJBPA-10-2017-0046.R1 \\
\hline Manuscript Type: & Original Article \\
\hline Keywords: & Curriculum development, engineering design, innovation, learning, failure \\
\hline \multicolumn{2}{|c}{} \\
\hline
\end{tabular}

SCHOLARONE ${ }^{\text {'N }}$

Manuscripts 


\section{Failure is an option: an innovative engineering curriculum}

\section{$\underline{\text { Abstract }}$ \\ Purpose}

Advancements and innovation in engineering design are based on learning from previous failures but students are encouraged to 'succeed' first time and hence can avoid learning from failure in practice.

The purpose of the study was to design and evaluate a curriculum to help engineering design students to learn from failure.

\section{Design/Methodology/Approach}

A new curriculum design provided a case study for evaluating the effects of incorporating learning from failure within a civil engineering course. An analysis of the changes in course output was undertaken in relation to graduate destination data covering 2006 to 2016 and student satisfaction from 2012 to 2017 and a number of challenges and solutions for curriculum designers were identified.

\section{Findings}

The design and delivery of an innovative curriculum, within typical constraints, can provide opportunities for students to develop resilience to failure as an integral part of their learning in order to think creatively and develop novel engineering solutions. The key issues identified were: the selection of appropriate teaching methods, creating an environment for exploratory learning, group and team assessments with competitive elements where practicable, and providing students with many different pedagogical approaches to produce a quality learning experience.

\section{Originality}

This case study demonstrates how to design and implement an innovative curriculum that can produce positive benefits of learning from failure. This model can be applied to other disciplines such as building surveying and construction management. This approach underpins the development of skills necessary in the educational experience to develop as a professional building pathologist.

\section{Keywords:}

Curriculum development, innovation, learning, failure, engineering design 


\section{Introduction}

Engineering design is a goal driven, problem-solving discipline that seeks to use technologies and materials to satisfy user requirements, taking into account applied constraints. The designer seeks to optimise outcomes within the available solution space, which drives a search for innovative and creative solutions to a combination of challenges that range from end-user demands to limitations of materials or application of techniques in new building design. In the search for innovation, some proposed solutions will inevitably fail to provide the desired outcomes (Sawyer, 2011; Syed, 2015). These failures can be an important feature of the innovation process, driving greater understanding, which can then be embedded into the design of future solutions. In this context, it is important that Engineers do not simply discard failures, but carry out rigorous analysis and evaluation so that the embedded knowledge is transferred to other engineers and other projects. Learning from failure should thus but an integral feature of an effective engineering design curriculum that trains graduates to learn from failure.

Within the context of the paper the use of the term 'failure' is interpreted as a universal feature of the engineering design process, which, if used correctly, has educational benefits (Sitkin, 1992; Petroski, 2016). Engineering students should be encouraged to attempt innovative, and potentially risky solutions, but this approach can be inhibited by constraints of the curriculum. This paper examines the literature on the nature of innovation and its links to the engineering design process. The link between learning from failure within engineering design, development and implementation, and the implications for students and course providers is discussed in the context of key areas of curriculum design that can be enhanced by learning from failure. A case study is then presented of a Civil Engineering course where teaching, learning and assessment principles were adapted to enhance learning from failure whereby design innovation, and risk taking, were encouraged. The paper reflects on the outcomes that have been recorded since introduction of the curriculum including monitoring of student satisfaction and destinations. The case study provides insights for other disciplines, such as surveying and construction management indicating the benefits of embedding the practice of learning from failure within a curriculum. 


\section{Literature Review}

\subsection{Innovation in Engineering Design}

The definition of innovation is ambiguous with Baregheh et al. (2009), suggesting upwards of 40 definitions currently in use, from which this paper has adopted:

Innovation is the multi-stage process whereby organizations transform ideas into new/improved products, service or processes, in order to advance, compete and differentiate themselves successfully in their marketplace.

The engineering design process is a parallel process involving both the feedforward and feedback of structured information relating to the product development (Bullinger and Warschat, 2012), resulting in a cyclical model of engineering development. The engineering design process must balance activities between those of the design theorist and the design pragmatist. Innovations in engineering design can evolve incrementally over time through a process of experiment and evaluation, in which an understanding of the nature of failure plays an important part (Petroski, 1998). Innovations emerge over time as individuals gather information about need, requirements, problems, potential outcomes and solutions along with consideration of the target market. Engineering design failures occur on a reasonably regular basis, and are traceable to a number of causes despite all efforts to prevent it being the case. There is a need for professionals in disciplines that inform construction design, such as building pathology, to build up the skills and attributes to analyse failure and identify the underlying causes, an important part of informing the innovation process.

\subsection{Influence of Innovation on Curriculum Design (how to learn from failure)}

For the purposes of this paper a curriculum is considered to be the process of learning for life within a framework that determines the context for transforming information into knowledge through the medium of a range of activities (Biesta, 2014). The curriculum needs to develop transformational learning to enable students to engage with risk taking and creating innovative solutions, whilst understanding the iterative nature of learning from failure and accepting failure as an integral part of the learning process (Limoncelli et al., 2012). A key aspect of innovation is the ability to identify and develop concepts that have originated in other ways and from other areas and to recognise that they 
have a potential application in relation to the specific problem for which a solution is being sought (Bullinger and Warschat, 2012). This implies an open-minded approach in which no concepts or ideas are rejected simply because they do not fit a pre-conceived model of a solution (Chesborough, 2006). This requires individuals to develop skills, tools and professional attributes to implement the solution. For the course designer this implies a need to establish a sound technical base while embedding an understanding of risk and failure within innovation and providing the tools to be able to analyse failures to establish cause. Over time a number of design support tools have been developed (Chakrabarti, 2013) that can support decision making in design. The engineering designer must be able to use these tools effectively in the reduction of the initial solution space, containing all viable solutions, taking into account relevant external factors.

The curriculum determines the skills, knowledge and professional attributes a graduate will develop and how prepared they are for employment (Knight and Yorke, 2002). Therefore, in relation to engineering design and innovation, where there are national standards overseen by professional bodies what scope is there to create a curriculum that embeds learning from failure within the teaching, learning and assessment practice and what is the impact of doing so? In comparing the performance of experienced versus novice scientists, Feist (2008) noted that:

- Expert scientists are more willing to modify or discard hypotheses than novices.

- Experts demonstrate more cognitive complexity when they discuss their domain.

- Novices solve problems and evaluate evidence based on more common sense representations; experts form abstract representations.

- Experts use chunking and mode-linked representations of large quantities of domain knowledge.

- Experts work forward from the information given; novices work backwards from a possible solution.

- Experts are more likely to discover useful analogies. 


\subsection{Challenges in curriculum design}

In the UK, the National Student Survey, the Teaching Excellence Framework and the Higher Education Academy are influencing the increasing use and reporting of innovative approaches to delivering, and assessing students (Medland, 2016) requiring academics to act as the catalyst and enablers for change (Louvel, 2013). Quality assurance processes, where metrics drive the assessment of quality, can lead to situations where the holistic student experience is not recognised (Teelken and Lomas, 2009). Students have considerable influence over teaching and assessment practice where satisfaction is taken as a proxy for quality of the student experience with the consequence that students get the learning experience they want and not necessarily what they need (Douglas et al., 2006). Students will go through a range of challenging emotional experiences during their learning, 
for example anxiety or anger, particularly if they have not 'succeeded'. These emotions can be a source of negative student feedback where a positive attitude towards building personal resilience to failure is not an embedded part of the learning process (Martin, 2002). When combined with robust reflection, learning from failures can instead result in interest, enjoyment and pride in tasks (Tulis and Ainley, 2011).

The typical measure of student success is through grades; high grades are derived from the provision of 'correct' answers. Within this context the low risk option for students is to practice for assessments and to find out what is deemed to be a correct answer (March, 1996). Academics need to have the skills to adapt to the increasing number of pedagogies (Dede, 2007) but under pressure to meet targets the low-risk option is to rely on established teaching methods and assessments that promote student satisfaction over creativity and open-ended complex problem solving (Binns, 2016; Voss et al., 2007). The conditions for innovative pedagogy that develop the academic resilience, critical thinking and problem solving skills of students need to be examined for their effective contributions to the iterative process of learning from failure. The curriculum also needs to ensure the learning experience within higher education is constructively aligned with the expectations of industry and professional bodies (Holdsworth and Hegarty, 2016), including issues of:

- How students learn - in particular interpretation of complex diagrams and taking notes.

- Learning how to work effectively in groups.

- Learning beyond the boundaries of any single discipline.

- Learning how to interpret behaviours and to distinguish between wants and needs.

- Developing effective communication skills using appropriate technology, maintaining the desire to keep up with technology developments for securely shared information

\subsection{Recommendations for Incorporating Learning from Failure into curriculum design}

The transition from practical experience to analysis, identified by Froyd et al. (2012), gives rise to the need to examine whether this results in a gap in student knowledge. In examining the factors that would influence curriculum design and delivery the following were also considered: 
1. The establishment of a sound technical base including the understanding that engineering design is an interdisciplinary area of study involving a range of additional non-engineering) skills and expertise (Dym et al., 2005).

2. Provision of support for individuals in developing personal, presentational, communication and listening skills (Moseley et al., 2005).

3. Support for individuals in developing note taking and diagramming skills to articulate innovation with content to provide the skills, tools and resources required for its implementation (Salter and Gann, 2003).

4. Concept development and the creation of opportunities for the cross-fertilisation of ideas and expose individuals to different means of thinking about, and solving, problems.

5. Creation of opportunities for group and team working with an emphasis on design and innovation with the focus on collaboration (Najdanovic-Visak, 2017).

6. Encouraging innovative approaches rather than conservative ones (O'Connor et al. 2008).

7. Embedding an understanding of risk and failure within innovation and providing the tools to be able to analyse failures to establish cause.

8. Developing an understanding of the user, their aims and goals (Joshi et al., 2012).

9. Access to, and the sharing of, information increasingly structured around electronic means.

10. Legislation, for instance regarding intellectual property, and its impact on the design process.

11. Grading schemes for projects involving collaboration with students that acknowledges different skills (Gavin, 2011).

12. Quality mechanisms and their operation (Tannock and Burge, 1994).

These issues can be grouped in relation to curriculum properties shown in Table 1. The starting point for the implementation of all of the above is the nature of a curriculum. The key features of Teaching, Learning and Assessment are discussed in further detail in the sections that follow. 


\subsubsection{Teaching - What to teach}

Study skills are essential preliminary core skills for learning including note taking, report writing, essay writing, and critical thinking etc. A coherent approach to embedding these skills within the delivery establishes the necessary foundation for knowledge development and deep learning for student success (Felder et al., 1998). The concept of establishing cause and effect in the curriculum design aids the process of prioritising the content, when and how it is delivered. Students cannot write professionally using appropriate language from an engineering design perspective until they know how to write professionally in general. They cannot write anything meaningful for content until they have the ability to think critically and articulate their thoughts. They cannot think critically until they have the knowledge to criticise and evaluate the information. They cannot evaluate information until they have established how to retrieve relevant information and so on. These elements must be at the core of the curriculum.

The course designer is expected to include the concepts of engineering design while providing access to the necessary tools along with an understanding of their use, operational implications and limitations whilst ensuring students are ultimately able to (Dym et al., 2005):

- Manage the ambiguities that inevitably result in the concept stages of the design process, requiring a combination of divergent thinking, ability to consider multiple potential outcomes, and fact-based convergent thinking.

- Place ideas within the context of the desired outcomes and of the associated systems concepts and dynamics.

- Manage the uncertainty associated with the engineering design process, particularly in the early stages of concept development that is associated with incomplete and imperfect models, incomplete information and potentially ambiguous objectives.

- Have an ability to estimate outcomes based on the identification of the key parameters driving the design.

- Communicate between the members of a design team using a variety of forms including verbal, 
diagrammatic mathematical models and parametric or numerical data.

The subject content and means of delivery are then open to various internal and external organisational influences in relation to identifying and implementing effective means for achieving the objectives of the curriculum (Anderson and Rogan, 2011). For example, the introduction of Building Information Modelling (BIM) has changed the process of procuring, constructing and operating built assets, which is increasingly dependent upon collaborative working. Whilst teamworking has always been an essential part of delivering projects, the nature of integration is now essential as more specialisms are included within the team across the project delivery and operation. The cross-fertilisation of ideas is crucial to innovation and are often formed from informal interactions in environments with very low cultural barriers to communication. This requires the course designer to enable individuals to develop personal, presentational and communication skills, including the ability to listen to others, indicating a need to create numerous opportunities for collaborative working where teams can share ideas and individuals engage with different approaches to thinking about, and solving, problems.

\subsubsection{Learning - How to teach}

There are a number of methods that can be used to provide a transformational learning experience that enables students to engage with risk taking and the creation of innovative solutions including:

- Problem-based learning (Davies, 2013; Dym et al., 2005), including analysing and learning through failure (Cavalline and Delatte, 2015)

- Research-based learning (Gosper and Ilfenthaler, 2014)

- 'Flipped classroom' (Potter and Jacobson, 2015)

- Assessment practice (Schkoda et al., 2013)

- Work based learning (Hartmann and Light, 2010)

- Digital learning technologies (Salmon, 2005)

A wide range of teaching approaches at the earlier stages of a student's learning experience exposes them to a diverse range of learning opportunities and helps them to develop life-long learning skills 
(Sunthonkanokpong, 2011). Key issues include ensuring appropriate balance between individual learning, collaborative learning, face-to-face and on-line teaching (Paechter and Maier, 2010). The successful use of technology for teaching delivery depends on a number of factors including the availability of resources and sufficient expertise of the designer to optimise the benefits of each technology effectively (Blin and Munro, 2008).

'Deep learning' requires the teaching team to implement the delivery methods with care to avoid students taking a strategic or surface learning approach to their studies and to ensure that the course context does not over-emphasise problem-solving procedures over conceptual understanding (Case and Marshall, 2004). The constructivist pedagogy is based on the theory that learners develop new understanding through taking responsibility for the process of building on and transforming their existing knowledge. Pedagogical methods that can be considered to be constructivist can be broadly described as inquiry-based for which there is evidence that there is a contribution towards deep learning including Problem Based Learning, case studies and Experiential Teaching Methods (Piercy et al., 2012).

\subsubsection{Assessment}

The appropriate assessment methodology that encourages learning from failure should recognise the learning process for individuals (Hughes and Jones, 2011). The issues that assessment practice needs to address include:

- Designing holistic assessments that combine technical knowledge and soft skills for each individual whilst working collaboratively.

- Moving towards open-ended, problem-based learning teaching methods that encourage and recognise learning through student reflection on the process rather than a specific 'correct' solution.

Formative assessment provides opportunities for learning from failure (Cauley, 2010). The skill for the curriculum designer is in getting the appropriate balance between formative and summative assessment that provides for learning through failure with sufficient motivation of students to engage with all the formative assessments (Harlen and James, 1997). 
The types of collaborative assessments that encourages highly motivated and creative approaches includes project simulations and involvement in competitions. Assessment of soft skills such as negotiation or conflict resolution within a collaborative assessment can become a source for negative student feedback if the process of learning and personal development are not adequately recognised. Grading requires acknowledgement of the learning associated with the process of problem solving in addition to the final solution (Bacon et al., 1999).

Quality assurance and enhancement can assist in identifying, reducing or removing barriers to implementing curriculum change. Quality reviews are shifting focus towards the learner and the learning experience, with more attention given to internal processes and internal motivators based on a research-informed, evidence-based and enhancement-led approach (Chung and Law, 2010). In formulating metrics, it is prudent to take note of Strathern's (1997) restatement of Goodhart's Law, namely that "when a measure becomes a target, it ceases to be a good measure"! The students themselves are the sole judges of whether or not satisfaction has been achieved. It follows that irrespective of flaws or complexity of any curriculum design and delivery what is transparent and measured is 'satisfaction'. How students interpret this, contextualise and score is irrelevant. The results of student feedback will drive curriculum change with the consequence that students will get what 'satisfies' them, but what may be required to learn may not always be what is found to be 'satisfying' (Wu et al., 2010).

\section{Study Methodology}

The purpose of the study was to design and evaluate a curriculum that included a change of content and delivery to focus more on developing the skills required for engineering design students to learn from failure. Based on principles discussed in Section 2, a course was redesigned to incorporate learning from failure more effectively in the curriculum.

Reigeluth and Frick (1999) examined research methods to assess their suitability for creating and improving instructional design theories and recommended "formative research" as a version of action research to improve design theory for designing instructional practices or processes. The process involves researchers and practitioners collaborating in the design, implementation and analysis of 
changes in practice. Formative evaluation is a methodology for improving curricula through answering questions such as "What is working?", "What needs to be improved?", and "How can it be improved?" to develop and test design theory on curriculum development (Reigeluth and Frick, 1999). The underlying logic of formative research is that any weaknesses that are found in the application of the theory may reflect weaknesses in that theory, and any improvements identified for the application may reflect ways to improve the theory. Formative research follows a case study approach and for this research, a holistic single case is appropriate when examining how to improve a design theory (Baxter and Jack, 2008).

The case study adopted involved the redesign of a 4-year civil engineering undergraduate degree from $2006 / 7$ to $2016 / 17$ with 328 students from the new curriculum graduating from 2012/13 onwards. Analysis of the impact of curriculum change was undertaken and data was examined in relation to identifying outcomes for employability (Graduate destination data) and student satisfaction (NSS survey data). Qualitative data from student feedback on module delivery was reviewed to examine any issues indicating student development or inhibition of creative and innovative engineering design solutions.

\section{Case Study}

The course team had the opportunity to revise a BSc (Hons) Civil Engineering course as a result of re-accreditation. At the same time recruitment was relatively low and there were insufficient graduates to achieve minimum numbers for specific course data on student satisfaction. The team therefore planned to design what was considered to be a new, exciting course and take an innovative approach to the curriculum design and delivery.

\subsection{Curriculum design}

The following sections describe the case study curriculum applied, and key considerations for curriculum designers at each stage of delivery. The stakeholders involved in the curriculum design included staff, students and members of the Industrial Liaison Panel (ILP), providing an industry perspective. The phasing out of a BSc (Hons) course in civil engineering and the implementation of a 
An outline of the curriculum applied is provided in Table 2

\section{[TABLE 2]}

Structuring and delivering the content required consideration of the appropriate order of delivery to ensure the skills are developed and applied as the basis of sound knowledge development. The core delivery team has educational qualifications and professional recognition for their teaching. Pedagogies that are based on knowledge building focus on working together, discourse and the shared goal of idea improvement (Ellis et al. 2010), which are embedded in the curriculum, and more evident within the work-based learning opportunities.

In each year, learning from failure was embedded into the course in the following areas:

- Year 1 - Core study skills, learning from feedback; structures design/testing; collaborative project to develop softer skills and integrate knowledge.

- Year 2 - Structure design/geotechnics; feedback week activities (sandwich placement); internal competition to design and constructing a scale structure.

- Year 3 - Structures; preparation for workplace and interview selection for placement; reflection in preparation for work placement module (and integrated with the Principals Award, which the students are all signed up to as part of being on the module), work placement and any subsequent summer experience. 


\subsection{Evaluation of curriculum redesign}

A range of different tools is available to examine the impact of curriculum change, including observation, student feedback at module and course level and quality assurance processes. The National Student Survey (NSS) is a measure of student satisfaction at $4^{\text {th }}$ year and can provide an indication as to how students' perception of the quality of the course is changing over time, as well as provide a comparative measure relative to similar courses across the sector. Due to low student numbers in earlier years, the first year where sufficient numbers of $4^{\text {th }}$ year students responding to the NSS survey was 2012. Figure 1 presents results for key indicators for the NSS survey from 2012-2017 for the case study Civil Engineering course at the institution presented in this study (HEFCE, 2017). During the period of 2012-14, overall student satisfaction remain relatively stagnant, falling during a period of staff shortage, and staff turnover in 2014. From 2015, overall student satisfaction has steadily increased, to $100 \%$ overall satisfaction in 2017 . A comparison of results in 2015 to sector averages found that the course scored significantly better than sector averages for civil engineering in teaching, assessment and feedback, academic support, organisation and management, personal development and overall satisfaction. While it is not possible to compare NSS results prior to curriculum change, this data provides some evidence that the new curriculum is meeting student needs.

\section{[FIGURE 1]}

Beyond student satisfaction, measures of graduate destinations can assist in evaluating the effectiveness of the course for preparing students for employment. The graduate destination data for the student cohorts in the case study course are presented in Figure 2 covering a 10 -year period and 328 graduates from 2006 to 2016 . The data presented in the figure provides an indication of a change in graduate employment in 2012/13 that coincides with the graduation of the first cohort of students completing the new curriculum. This period coincides with increased student numbers, enabling the 
course to reach sufficient graduating students, with sufficient response rates, to have data for NSS

results. Whilst it is not possible to confirm that the curriculum changes directly contributed to improved recruitment, it remains a fact that these factors coincide.

\section{[FIGURE 2]}

The graduates of the revised curriculum are more likely to respond to requests for information about their next career stages, reducing the 'unknown' responses indicating a greater engagement with their learning experience and willingness to provide feedback for future developments. The number of students obtaining employment in their discipline is markedly higher, as is the number seeking further study to complete their education for a Chartered Engineer career path.

Additional evidence on whether students responded positively to the incorporation of learning from failure in the curriculum can be found in student confidence to engage in more risk taking behaviours. In the case study civil engineering programme, year two undergraduate students have benefited from learning through an internal competition to design and construct a scale structure. In 2016/17, the entire year entered a national competition of a similar nature sponsored by the Institution of Structural Engineers and one team went on to beat other university teams that included students at higher levels, including MSc students. Module surveys provide direct student feedback across various modules and help to identify key areas that students are deriving value from the course. Across module surveys, multiple students indicate that the methods of course delivery make the subjects interesting. For example, one student commented:

"The way the course has been presented to students is great, the method of teaching is excellent and the course content is interesting" (response to 2017/18 module survey)

Students also indicated that they enjoy learning from industry experts, providing a contextualisation of real world problems. For example, students commented:

"sharing his past experiences in the Civil Engineering industry [...] is great to learn from" (response to 2016/17 module survey) 
"bringing real companies to come and speak to us, so we can hear other people experiences." (response to $2016 / 17$ module survey)

Students also indicate that the course is preparing them for the world of work. For example, students commented:

"helps to give an understanding of the industry we are about to embark upon"

(response to 2017/18 module survey)

“feedback from last year's placements, really helped in terms of forward thinking for short and long term goals” (response to 2017/18 module survey)

Together, the analysis of overall student satisfaction, graduate destinations and direct student feedback implies some positive implications of the curriculum redesign. In addition, the course has received accreditation by the Joint Board of Moderators (JBM), who commented favourably upon the inclusion of an Industrial Liaison Panel (ILP) in steering the course content and delivery and the influence of industry members in supporting course developments.

Notwithstanding the positive results of the implementation, there are areas that have been identified where improvements can be made. For example, the JBM indicated the final year MEng group project could be enhanced if the team could provide students with some design office space using one day design studio sessions involving local practising architects or engineers as appropriate. This could enhance the opportunity for students to learn from industry practitioners further.

\section{Discussion and Conclusions}

The civil engineering course curriculum appears to have successfully embedded learning from failure within the student experience. Positive changes were identified and a number of challenges addressed that can be applied to any surveying or construction management course: 
- The selection and application of appropriate teaching, learning and assessment methods is critical. To develop professional skills such as persistence, dealing with uncertainty, critical thinking, and analytical thinking within a multi-disciplinary context the curriculum has to create learning environments within which students may experience failure and learn from exploratory learning. In our case study, incremental developments continue as the course is delivered, informed by feedback from staff, students, the ILP and the JBM by placing the focus on the learner, in the same context identified by Hubball and Burt (2004).

- Each assessment and its purpose was made as open-ended as possible across all subjects and years.

- Collaborative working required a shift in teaching, learning and assessment practice so that formative and summative assessments focused on acknowledging the learning process in addition to the output. The team's experience aligns with the findings of English et al. (2004) in that it is possible to influence student approaches to learning, particularly through assessment, which, in turn influences students' perceptions of task requirements and hence their approach to learning.

- Embedding a wider range of methods of delivery for working within teams more closely aligned with professional industry was enhanced by engaging in internal and external student competitions.

- There are considerable benefits to the inclusion of a 12-week full-time work-placement. The redesign of activities, use of technologies, increased exposure to practical learning at university and the workplace contributed towards mitigating against epistemological barriers, providing opportunities for greater personal development (Meyer and Land, 2006).

- The learning environment needs to recognise the link between design innovation and risk in which students are not automatically penalised for a failed design, but are encourage to analyse, learn from any failures and are rewarded accordingly for their knowledge achievement. Such a learning process has been, and continues to be, a characteristic of real-world engineering, which students need to be aware of within the context of their course. 
- A team has to have the necessary teaching skills and resources to implement a wide range of methods of delivery and assessment.

o The teaching team need the academic freedom to innovate in teaching and share best practice whilst learning from other disciplines.

○ The curriculum designer needs academic freedom to design, implement and review the curriculum with opportunities for reflection as per the process of engineering design to achieve the optimum solution.

Our study has demonstrated that the design and delivery of an innovative curriculum, within typical constraints, can provide opportunities for students to develop resilience to failure as an integral part of their learning in order to think creatively and develop novel engineering solutions. This model can be applied to other disciplines such as building surveying and construction management. This approach underpins the development of skills necessary in the educational experience to develop as a professional building pathologist. 
Anderson, T.R. and Rogan, J.M. (2011), "Bridging the educational research-teaching practice gap:

Curriculum development, Part 1: Components of the curriculum and influences on the process of curriculum design", Biochemistry and molecular biology education, 39(1), 68-76.

Bacon, D.R., Stewart, K.A. and Silver, W.S. (1999), "Lessons from the best and worst student team experiences: How a teacher can make the difference", Journal of Management Education, 23(5), 467-488.

Baregheh, A., Rowley, J., and Sambrook, S. (2009), "Towards a multidisciplinary definition of innovation”, Management Decision, 47(8), 1323-1339.

Baxter, P., and Jack, S. (2008), "Qualitative case study methodology: Study design and implementation for novice researchers", The qualitative report, 13(4), 544-559.

Biesta, G. (2014), "Pragmatising the curriculum: bringing knowledge back into the curriculum conversation, but via pragmatism", The Curriculum Journal, 25(1), 29-49.

Binns, C. (2016), "Under pressure: an exploration of the module design experiences of academic staff employed in one UK university", Journal of Further and Higher Education, 41(6), pp. 817-830.

Blin, F. and Munro, M. (2008), “Why hasn't technology disrupted academics' teaching practices? Understanding resistance to change through the lens of activity theory", Computers \& Education, 50(2), 475-490.

Bullinger, H.J., and Warschat, J. (Eds.), (2012), Concurrent simultaneous engineering systems: the way to successful product development. Springer Science \& Business Media, London.

Case, J., and Marshall, D. (2004), "Between deep and surface: procedural approaches to learning in engineering education contexts", Studies in Higher Education, 29(5), 605-615.

Cauley, K.M. and McMillan, J.H. (2010), “Formative assessment techniques to support student motivation and achievement", The Clearing House: A Journal of Educational Strategies, Issues and Ideas, 83(1), 1-6. 
Cavalline, T., and Delatte, N. (2015), "Learning from the World Trade Centre Collapse - Use of a Failure Case Study in a Structures and Materials Laboratory Course", Journal of Engineering Technology, 32(2), 2-17.

Chakrabarti, A. (Ed.), (2013), Engineering design synthesis: understanding, approaches and tools. Springer Science \& Business Media, London.

Chesborough, H., Vanhaverbeke, W. and West, J. (Eds.), (2006), Open innovation: Researching a new paradigm. Oxford University Press on Demand.

Chung, D., and Law, S. (2010), "Quality assurance in post-secondary education: the student experience", Quality Assurance in Education, 18(4), 250 - 270.

Davies, H.C. (2013), "Integrating a multi-university design competition into a mechanical engineering design curriculum using modern design pedagogy", Journal of Engineering Design, 24(5), 383396.

Dede, C. (2007), Transforming education for the 21st century: New pedagogies that help all students attain sophisticated learning outcomes", NCSU Friday Institute, Raleigh, NC: U.S..

Douglas, J., Douglas, A., and Barnes, B. (2006), “Measuring student satisfaction at a UK university", Quality Assurance in Education, 14(3), 251-267.

Dym, C.L., Agogino, A.M., Eris, O., Frey, D.D. and Leifer, L.J. (2005), “Engineering design thinking, teaching, and learning”, Journal of Engineering Education, 94(1), 103-120.

Ellis, G.W., Rudnitsky, A.N. and Moriarty, M. A. (2010), “Using knowledge building to support deep learning, collaboration and innovation in engineering education", in Frontiers in Education Conference (FIE), Washington DC, Oct 27-30 2010, IEEE pp. T2J-1 - T2J-5.

English, L., Luckett, P. and Mladenovic, R. (2004), “Encouraging a deep approach to learning through curriculum design", Accounting Education, 13(4), 461-488.

Feist, G. (2008). The Psychology of Science and the Origins of the Scientific Mind, Yale University Press, London. 
Felder, R.M., Felder, G.N. and Dietz, E.J. (1998), “A longitudinal study of engineering student performance and retention. V. Comparisons with traditionally-taught students", Journal of Engineering Education, 87(4), 469-480.

Froyd, J.E., Wankat, P.C. and Smith, K.A. (2012), "Five major shifts in 100 years of engineering education", Proceedings of the IEEE, 100(Special Centennial Issue), 1344-1360.

Gavin, K. (2011), “Case study of a project-based learning course in civil engineering design”, European Journal of Engineering Education, 36(6), 547-558.

Gosper, M. and Ilfenthaler, D. (Eds.), (2014). Curriculum Models for the $21^{\text {st }}$ Century, Springer, London.

Harlen, W. and James, M. (1997), “Assessment and Learning: differences and relationships between formative and summative assessment", Assessment in Education: Principles, Policy \& Practice, $4(3), 365-379$.

Hartmann, E.A. and Light, B. (2010), Promoting Innovation by Work Based Learning. [online] available at: http://internationalmonitoring.de/fileadmin/Downloads/Trendstudien/TS_Hartmann_Light_engl.pd $\underline{f}$ (accessed 01 December 2017).

Higher Education Funding Council for England (HEFCE). (2017), National Student Survey [online]

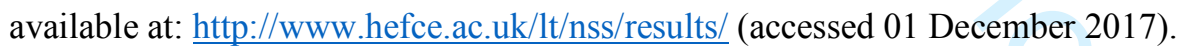

Holdsworth, S. and Hegarty, K. (2016), "From praxis to delivery: a Higher Education Learning Design Framework (HELD)", J. Cleaner Production, 122, 176-185.

Hubball, H. and Burt, H. (2004), “An integrated approach to developing and implementing learningcentred curricula", International journal for academic development, 9(1), 51-65.

Hughes, R.L. and Jones, S.K. (2011), “Developing and assessing college student teamwork skills", New Directions for Institutional Research, 2011(149), 53-64. 
Joshi, S., Morkos, B., Shankar, P., Summers, J.D. and Mocko, G.M. (2012), "Requirements in Engineering Design: What are we teaching?", Tools and Methods for Competitive Engineering, (38).

Knight, P.T. and Yorke, M. (2002), “Employability through the curriculum”, Tertiary Education \& Management, 8(4), 261-276.

Limoncelli, T., Robbins, J., Krishnan, K. and Allspaw, J. (2012), “Resilience Engineering: Learning From Failure", Communications of the ACM 55(11), 40-47.

Louvel, S. (2013), "Understanding change in higher education as bricolage: how academics engage in curriculum change", Higher Education, 66(6), 669-691.

March, J.G. (1996), “Learning to be risk averse”, Psychological Review, 103(2), 309.

Martin, A. (2002), "Motivation and academic resilience: Developing a model for student enhancement", Australian Journal of Education, 46(1), 34-49.

Medland, E. (2016), “Assessment in higher education: drivers, barriers and directions for change in the UK", Assessment \& Evaluation in Higher Education, 41(1), 81-96.

Meyer, J.H. and Land, R. (2006), Overcoming barriers to student understanding: Threshold concepts and troublesome knowledge, Routledge, Abingdon.

Moseley, D., Elliott, J., Gregson, M. and Higgins, S. (2005), “Thinking skills frameworks for use in education and training", Journal of British Educational Research, 31(3), 367-390.

Najdanovic-Visak, V. (2017), “Team-based learning for first year engineering students”, Education for Chemical Engineers, 18, 26-34.

O'Connor, G.C., Ravichandran, T. and Robeson, D. (2008), "Risk management through learning: Management practices for radical innovation success", Journal of High Technology Management Research, 19(1), 70-82.

Paechter, M. and Maier, B. (2010), “Online or face-to-face? Students' experiences and preferences in e-learning", Internet and Higher Education, 13, 292-297. 
Piercy, N., Brandon-Jones, A., Brandon-Jones, E. and Campbell, C. (2012), "Examining the effectiveness of experiential teaching methods in small and large OM modules", International Journal of Operations \& Production Management, 32(12), 1473-1492.

Petroski, H., 1998. Invention by Design: How Engineers Get from Thought to Thing. Harvard University Press, Cambridge, U.S.

Petroski, H. (2016), “To Engineer is Human: The Role of Failure in Successful Design”, Defense AR Journal, 23(1), 106-109.

Potter, L. and Jacobson, B. (2015), Lessons Learned from Flipping a First-Year Industrial Engineering Course. In IIE Annual Conference. Proceedings 2015, Institute of Industrial Engineers (IIE), pp. 1304.

Reigeluth, C.M. and Frick, T.W. (1999), "Formative research: A methodology for creating and improving design theories", Reigeluth, C.M. (Ed.), Instructional-design theories. Routledge, Abingdon, 633-652.

Salmon, G., 2005. Flying not flapping: a strategic framework for e-learning and pedagogical innovation in higher education institutions. ALT-J, Research in Learning Technology, 13(3), 201218.

Salter, A. and Gann, D. (2003), "Sources of ideas for innovation in engineering design”, Research Policy, 32(8), 1309-1324.

Sawyer, R.K. (2011), Explaining creativity: The science of human innovation. Oxford University Press, Oxford.

Schkoda, R.F., Schweisinger, T.A. and Wagner, J.R. (2013), “An improved undergraduate mechanical engineering laboratory structure and curriculum: design and assessment”, International Journal of Mechanical Engineering Education, 40(3), 182-196.

Sitkin, S.B. (1992), "Learning through failure: the strategy of small losses", Research in Organizational Behavior, 14, 231-266. 
Strathern, M. (1997), “Improving Ratings. Audit in the British University System”, European Review, $5,305-321$.

Sunthonkanokpong, W. (2011), "Future global visions of engineering education”, Procedia Engineering, 8, 160-164.

Syed, M. (2015), Black box thinking: The surprising truth about success (and why some people never learn from their mistakes). Hodder \& Stoughton, London.

Tannock, J.D.T. and Burge, S.E. (1994), “The EPC Model for Quality Assurance in Higher Education”, European Journal of Engineering Education, 19(3), 263-274.

Teelken, C. and Lomas, L. (2009), "How to Strike the Right Balance Between Quality Assurance and Quality Control in the Perceptions of Individual Lecturers: A comparison of UK and Dutch higher education institutions", Tertiary Education and Management, 15(3), 259-275.

Tulis, M. and Ainley, M. (2011), “Interest, enjoyment and pride after failure experiences? Predictors of students' state-emotions after success and failure during learning in mathematics", Educational Psychology, 31(7), 779-807.

Voss, R., Gruber, T. and Szmigin, I. (2007), "Service quality in higher education: The role of student expectations", Journal of Business Research, 60(9), 949-959.

Wu, J.H., Tennyson, R.D. and Hsia, T.L. (2010), “A study of student satisfaction in a blended elearning system environment”, Computers \& Education, 55(1), 155-164. 
Page 25 of 30

International Journal of Building Pathology and Adaptation

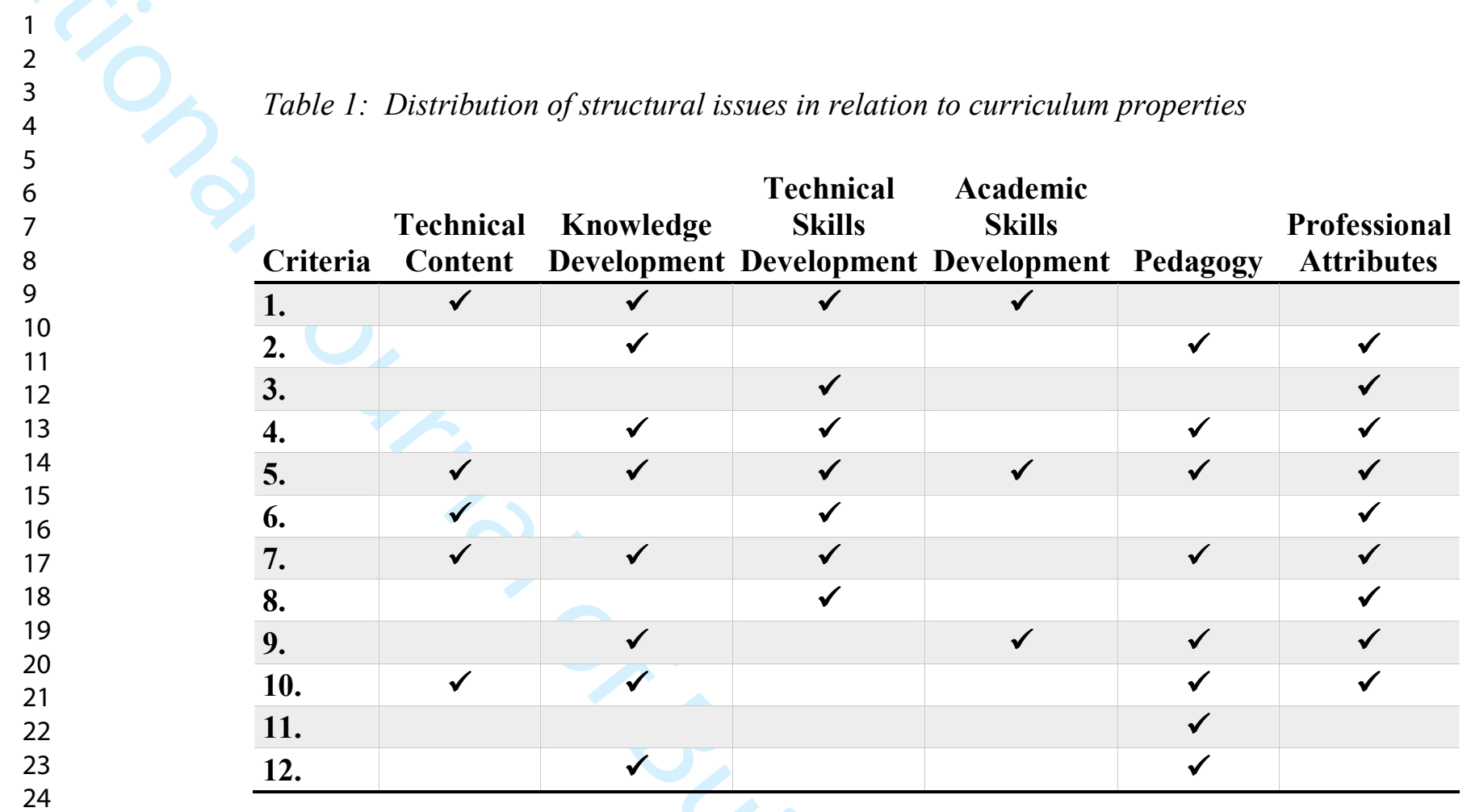

25

26

27

28

29

30

31

32

33

34

35

36

37

38

39

40

41

42

43

44

45

46

47

48

49

50

51

52

53

54

55

56

57

58

59

60 
Table 2. Curriculum design

\begin{tabular}{|c|c|c|c|}
\hline & $x^{2}=$ & Term 2 & Summer \\
\hline Year 1 & $\begin{array}{l}\text { - Academic skills are the priority, skills and } \\
\text { technologies are taught and applied, forming a sound } \\
\text { basis for future learning. } \\
\text { - Introduction to collaborative working and overcoming } \\
\text { barriers to learning } \\
\text { - Establishing the appropriate professional attributes, } \\
\text { ethics, professional writing, dealing with conflict and } \\
\text { negotiation in the context of engineering design. } \\
\text { - Technical skills including the ability to work safely in } \\
\text { a laboratory } \\
\text { - Learning to design, undertake, record, analyse and } \\
\text { report on laboratory tasks/experiments. }\end{array}$ & $\begin{array}{l}\text { - Commencing basic understanding of } \\
\text { technical content are in place. } \\
\text { - Knowledge development on technical } \\
\text { content, ideally informed by current research } \\
\text { and innovation with opportunities to apply } \\
\text { knowledge in different contexts, including } \\
\text { team competitions. } \\
\text { - The first summative assessments enable } \\
\text { students to learn from previous feedback. }\end{array}$ & $\begin{array}{l}\text { - If possible, employment at the } \\
\text { end of Cycle is desirable in order } \\
\text { to develop employability, } \\
\text { building professional attributes } \\
\text { and gaining the necessary } \\
\text { experience of working } \\
\text { effectively with others as an } \\
\text { essential engineering design } \\
\text { skill. }\end{array}$ \\
\hline Year 2 & $\begin{array}{l}\text { - Encourage students to regularly reflect on their } \\
\text { academic progress and achievements, and recognise } \\
\text { factors enabling their learning, emphasizing learning } \\
\text { from feedback. } \\
\text { - Technical content develops subject knowledge in order } \\
\text { to provide the basis for improved creative problem } \\
\text { solving. } \\
\text { - Emphasis on formative assessment to develop deeper } \\
\text { learning from meaningful reflection. }\end{array}$ & $\begin{array}{l}\text { - Focus on developing skills and knowledge to } \\
\text { put into practice a deeper understanding of } \\
\text { the subjects } \\
\text { - Identify, define, analyse and resolve } \\
\text { engineering problems, based upon a level of } \\
\text { engineering knowledge. } \\
\text { - Summative assessment that conform to } \\
\text { typical expectations for internal quality } \\
\text { assurance and third party accreditation are } \\
\text { adopted as an expected benchmark. }\end{array}$ & $\begin{array}{l}\text { - Putting all the previous } \\
\text { knowledge and skills into } \\
\text { practice within a relevant work- } \\
\text { based learning to contextualise } \\
\text { and develop their skills } \\
\text { - A first opportunity for work- } \\
\text { based learning are unarguable } \\
\text { although this cannot be made } \\
\text { mandatory. }\end{array}$ \\
\hline & \multicolumn{3}{|c|}{$\begin{array}{l}\text { - Continue to develop and broaden the existing knowledge and skills relevant to the course until course completion (in the case study a further } 2 \\
\text { cycles is required to MEng level). } \\
\text { - Continued use of teaching, learning and assessment methods that align with the further development of professional engineering attributes, } \\
\text { employability skills, reflection, teamwork and leadership. } \\
\text { - At the end of the cycle, a full term of work-based experience that often follows into summer placement with further experience. } \\
\text { - The work-based learning enables greater understanding due to the ability to contextualise subject content. }\end{array}$} \\
\hline
\end{tabular}




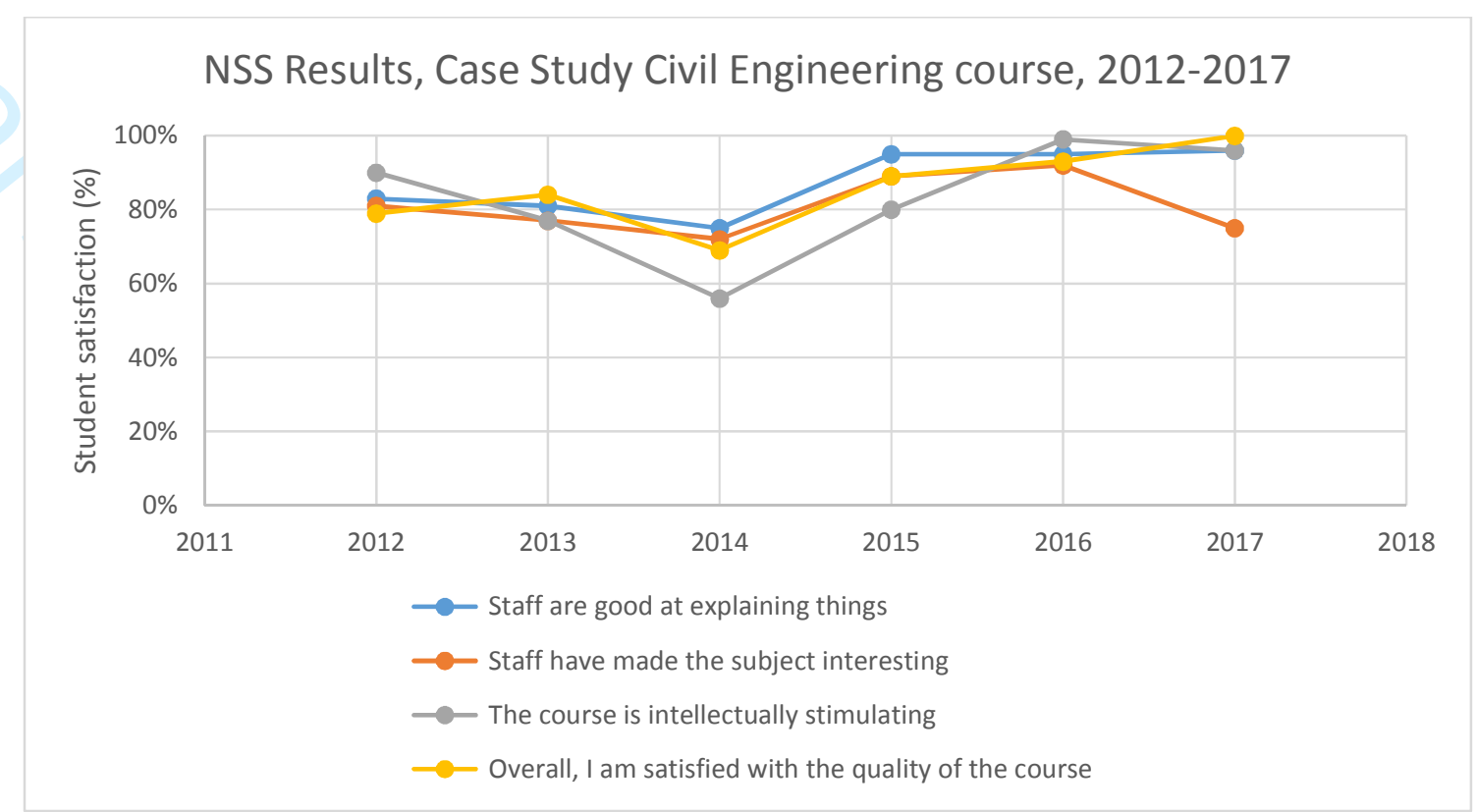

Figure 1 Selected NSS results 2012-2017 (HEFCE 2017) 
Figure 2 Graduate Destinations 2006 - 2016 for the case study institution, as recorded by the institution 


\section{IJBPA - 10 - 2017 - 0046 Failure is an option: an innovative engineering curriculum}

\section{Reviewer Comments and Author responses}

\section{Reviewer 1 Comments}

Overall comments: this paper has the potential to offer the IJBPA academic community something positive. This reviewer is curious as to why the author(s) have decided to publish in this journal. Perhaps the paper might be better submitted to a journal more focused on engineering design education.

The style/approach may offer some challenges in terms of focused application by the potential readers of the journal. For example, there is no real discourse around the case study methodology chosen and the justification of same. There should be some written section on the approach taken to research rather than just presenting the case study outcomes.

Currently, the paper would merit a further review and the inclusion of some underpinning theory related to assessment, teaching and learning. A more aligned background would be more appropriate, see comments later.

The comments offered are done in an attempt to allow the authors to improve on this iteration.

Title: The title of the paper requires a context as currently does not fully capture the essence of the paper. Introduction: What is lacking is the reference to academic literature on learning, teaching and assessment.

Course Design and Implementation: this section of the paper offers a very detailed background to the topic. It might be more appropriate to review this section and offer a reworked version where a more concise and focused version is included.

The section 4.1 on curriculum has been included without any real justification as to its need in the paper. Currently the content of this section (4.1) appears to be too detailed and some parts do not add real value. Maybe consider the content and reflect on where there is overlap with a view to refining same. What merit do sections 4.3.1 - 4.3.7 offer?

Originality: The paper contains some originality, however the way in which it is presented would require some reflection.

Relationship to Literature: The paper presents literature from many different areas of education and in particular curriculum development. The paper would be improved if the authors addressed the three strands of learning, teaching and assessment in a more coherent way Methodology: The paper lacks an in-depth positioning in regard to methodology. See general comments.

Implications for research, practice and/or society: This section lacks the necessary depth.

\section{Author Responses}

The curriculum design, although applied to a civil engineering course, is relevant across many specialisms including surveying and construction management. The authors see direct links between graduates who have developed skills for learning from failure and the field of building pathology, where assessing building failure and identification of solutions is a key element of the profession.

A significant reorganisation of the paper has taken place to address this. A methodology section has been added to contextualise the study and further detail on the case study and measurable outcomes are presented.

The literature review has been restructured to include specific consideration of teaching, learning and assessment. Additional citations to increase the robustness of the literature review.

We appreciate the very constructive comments provided by the reviewer, and we hope that the reorganisation and presentation of the paper are now much improved.

Title has now been amended

See comment above - restructuring and additional consideration of teaching learning and assessment should now be more obvious, with additional citations included to further reinforce these topics.

This section was reduced considerably to ensure it was more focused.

Section 4 was substantially reorganised, and content presented in sections 4.3.1 to 4.3.7 was converted into a table to enable a shorter narrative to address the presentation of curriculum structure and justify the need to include the content.

We have undertaken a considerable rewrite, which we hope addresses some of the key presentation issues identified by the reviewers. In addition, changes include the presentation of data supporting the argument for new curriculum design approaches in creating innovative engineers through a philosophy of learning from failure, which we feel helps to address this point.

The changes include a restructuring of the paper to focus more clearly on these topics.

The methodology section has been developed and includes details on the data collected and analysed.

Changes include reflection on the additional data to more clearly indicate the differences between theory and practice for the case study 
Methodology:

The paper does not include research methods to support a case study. The paper does not include data or analysis to support any conclusions.

Results: No. The paper does not include adequate data to analyse and draw conclusions.

Implications for research, practice and/or society: The paper does not bridge the gap between theory and practice as it does not include findings supported by data/evidence.
The restructuring provides a more logical and structured presentation of the problem, issues, methodology, discussion and findings.

\section{Author Responses}

A significant restructuring of the paper has been undertaken to address this key observation by the reviewer. Notably a methodology section has been developed and the case study section has been clearly laid out to improve presentation of evidence including details on the data collected and analysed. We are not aware of examples in the literature of where a civil engineering course has been redesigned, applied and analysed in this manner. This may not have been communicated sufficiently in the first draft, and we hope that the revision improves the presentation such that we more clearly provide supporting evidence for the argument that new curriculum design through a philosophy of learning from failure can assist in developing innovative engineers.

We recognise that this was a significant flaw in the first draft. A methodology section has been developed and the case study section more clearly presents details on the data collected and analysed to support our conclusions. As stated, significant changes have been included in section 4 to present evidence and reflection.

We thank the reviewers for their constructive comments, and have undertaken a significant rewrite to address these key issues. Changes include reflection on the additional data to more clearly indicate the linkages between theory and practice for the case study. 